\title{
Concepções sobre práticas alimentares em mulheres de camadas populares no Rio de Janeiro, RJ, Brasil:
}

transformações e ressignificações

\author{
Tatiana Coura Oliveira ${ }^{(a)}$ \\ Dina Czeresnia ${ }^{(b)}$ \\ Eliane Portes Vargas ${ }^{(c)}$ \\ Denise Cavalcante de Barros ${ }^{(d)}$
}

Oliveira TC, Czeresnia D, Vargas EP, Barros DC. The food practice concepts of Rio de Janeiro's lower class women: transformation and reinterpretation. Interface (Botucatu).

2018; 22(65):435-46.

The present qualitative study concerns the food practice concepts and meanings of lower-class overweight women. Issues associated with social and cultural conditions in urban areas are part of a transformation process marked by lack of time and the quest of convenience. Ultra-processed food, athough seen as unnecessary in the past are nowadays considered a basic staple by the lower class in Rio de Janeiro. This new reality confronts the contemporary discourse about healthy eating, which is focused on the demand for consuming "healthier" products. Such scenario demands the informants a constant reinterpretation about the act of "eating", oscillating between pleasure and guilt. The current study discusses the need of understanding these expressions based on a restricted framework of possibilities determined by micro and macrosocial aspects. These aspects shape the contemporary mode of food production and distribution in our society.

Keywords: Food practices. Culture. Overweight.
Nesta pesquisa de cunho qualitativo buscou-se compreender as concepções e os sentidos atribuídos às práticas alimentares por mulheres de camadas populares com excesso de peso. Questões associadas às condições sociais e culturais da vida urbana configuram um processo de transformações marcado pela escassez de tempo e de busca de praticidade. Produtos ultraprocessados, antes vistos como supérfluos, são agora considerados básicos na alimentação desse grupo de mulheres no Rio de Janeiro. Esta realidade se confronta com o discurso contemporâneo da alimentação saudável que, ao fomentar uma demanda de consumo de produtos considerados benéficos à saúde, exige das informantes constantes ressignificações em relação ao "comer" que oscilam entre o prazer e a culpa. Discute-se a necessidade de compreender tais expressões dentro de um quadro de possibilidades restrito e determinado por aspectos micro e macrossociais que conformam os modos contemporâneos de produção e distribuição de alimentos em nossa sociedade.

Palavras-chave: Práticas alimentares. Cultura. Excesso de peso. (a) Instituto de Ciências Biológicas e da Saúde, Universidade Federal de Viçosa. Rodovia MG230, Km 7, Campus de Rio Paranaíba. 38810-000. Rio Paranaíba, MG, Brasil. tatiana.coura@ufv.br (b) Departamento de Epidemiologia e Métodos Quantitativos em Saúde, Escola Nacional de Saúde Pública Sergio Arouca, Fundação Oswaldo Cruz. Rio de Janeiro, RJ, Brasil. dina@ensp.fiocruz.br

(c) Instituto Oswaldo Cruz, Fundação Oswaldo Cruz. Rio de Janeiro, RJ, Brasil. epvargas@ioc.fiocruz.br (d) Tecnologista em Saúde, Escola Nacional de Saúde Pública Sergio Arouca, Fundação Oswaldo Cruz. Rio de Janeiro, RJ, Brasil. barrosdc@ ensp.fiocruz.br 


\section{Introdução}

O desenvolvimento econômico e o progresso em relação à produção, conservação e distribuição reduziram consideravelmente dificuldades que pesavam sobre a disponibilidade alimentar instalando, de maneira durável, um cenário social de maior abundância nas sociedades ocidentais ${ }^{1}$. Na atualidade há maior acesso a alimentos, bem como a informações, serviços e ações de saúde em comparação à situação de décadas passadas ${ }^{2-4}$. Entretanto, essa maior disponibilidade não correspondeu necessariamente a uma melhora no padrão alimentar das famílias brasileiras ${ }^{5}$. Observou-se, apesar da importante redução nos indicadores de desnutrição infantil e déficit estatural, uma nova forma de carência alimentar ${ }^{4}$. Isto porque alimentos calóricos, mas pobres do ponto de vista nutricional passaram a fazer parte da alimentação

Mudanças nos hábitos alimentares favoreceram o crescimento dos indicadores de excesso de peso e obesidade, incorporados tanto como parte de um determinado modo de vida, bem como em consequência dele ${ }^{7}$. Apesar dos dados epidemiológicos evidenciarem o aumento generalizado do problema independentemente do sexo em diferentes níveis socioeconômicos, sua face mais acentuada se apresenta entre as mulheres. Situação agravada entre aquelas de menor renda seja por sua baixa flexibilidade em relação à aquisição de alimentos ou ainda por inequidades relativas ao acesso a serviços, ou à possibilidade de exercerem hábitos considerados saudáveis ${ }^{8,9}$. Hoffmann ${ }^{10}$ evidenciou que mulheres negras, com baixa escolaridade e renda, multíparas e em condições de vida urbana têm maior probabilidade de ser obesas.

Estudos socioculturais, ao privilegiarem abordagens compreensivas da alimentação, podem lançar luz sobre questões ainda pouco exploradas, relativas a aspectos culturais da realidade social que se conectam ao cotidiano da vida das pessoas. A cultura aqui é entendida como um conjunto de significados e símbolos compartilhados que modelam as práticas alimentares se manifestando de modo diferenciado entre os grupos sociais. Como uma teia de representações permeáveis às mudanças, ela funciona como uma matriz de percepção, interpretação e ação que conecta memória e tradição às novas experiências alimentares ${ }^{11}$. Tais concepções e práticas alimentares contemporâneas se caracterizam pelo desequilíbrio entre a extensa cadeia produtiva e questões relacionadas à acessibilidade, palatabilidade, comunicação e publicidade, que interferem nas decisões de aquisição e consumo. Portanto, as questões relativas à alimentação não podem ser apreendidas por uma perspectiva atenta unicamente aos processos mais amplos e macrossociais desta mesma realidade. Por outro lado, pensar o consumo a partir dos pressupostos de uma escolha racional, na qual os indivíduos de camadas populares selecionam e consomem alimentos exclusivamente a partir de preferências e/ou constrangimentos financeiros seria simplificar muito a questão. Neste sentido o objetivo deste artigo é descrever como as mudanças e as permanências nas práticas alimentares se configuram em relação aos próprios modos de vida a partir da narrativa de mulheres em situação de sobrepeso e obesidade.

\section{Metodologia}

Este estudo adota uma abordagem qualitativa de cunho etnográfico visando compreender como as mudanças nas práticas alimentares cotidianas de um grupo de mulheres de camadas populares estão associadas ao crescimento da obesidade enquanto problema de saúde pública ${ }^{12}$. Foram realizadas vinte e uma entrevistas entre setembro e novembro de 2015, com usuárias em um Centro de Saúde situado em um conjunto de comunidades da zona Norte do Rio de Janeiro, adotando-se o princípio da saturação das questões abordadas na composição do estudo ${ }^{13}$. Houve aprovação no Comitê de Ética em Pesquisa. 


\section{Caracterização das informantes}

Em relação ao diagnóstico nutricional, dentre as 21 entrevistadas 18 possuíam obesidade em seus diferentes níveis: grau I ( $n=$ oito), grau II $(n=$ cinco) e grau III $(n=$ cinco), e as demais $(n=$ três) tinham sobrepeso. Com idades compreendidas entre 23 e 64 anos, parte das informantes era proveniente da zona rural nordestina $(n=$ cinco), ou zona rural do Espírito Santo $(n=u m)$, ou ainda do interior do Rio de Janeiro $(n=u m)$ cujas histórias singulares de migração aconteceram como tentativas de melhores condições de vida; as demais (14) haviam nascido na própria comunidade ou periferia urbana do Rio de Janeiro, sendo possível encontrar alguns relatos de migração dos pais (dois) ou avós paternos ou maternos (três) vindos, em sua maioria, do interior de outros estados brasileiros.

Nos arranjos familiares houve um predomínio do tipo mulher e cônjuge com filhos, sendo mais frequente a união consensual com inicio na juventude. Havia ainda duas entrevistadas solteiras com filhos, uma viúva e uma com o marido no cárcere.

Em relação à ocupação, treze entrevistadas trabalhavam no setor formal em atividades como limpeza e serviços gerais (seis), serviços de saúde (quatro), cozinheira (um), auxiliar de escritório (um), técnica em enfermagem (um). Entre aquelas ligadas ao setor informal de trabalho, três exerciam serviços de limpeza em domicílios, uma era manicure e uma catadora de material reciclável. Havia duas pensionistas do Instituto Nacional do Seguro Social (uma por tempo de contribuição; outra por viuvez) e uma desempregada. O salário destas mulheres era a única fonte de renda para uma considerável parte das famílias ( $n=$ nove), sendo também importante na complementação financeira das demais $(n=12)$. Quanto à escolaridade, apesar de estarem majoritariamente inseridas em ocupações com menor exigência escolar, há um predomínio de mulheres com ensino médio completo ( $n=$ dez), seguido de ensino fundamental ( $n=$ sete) e ensino superior ( $n=$ três), completo ou incompleto. Apenas uma das informantes relatou nunca ter frequentado uma escola apesar de não ser analfabeta.

\section{Resultados e discussão}

\section{Transformações, permanências e incorporações nas práticas alimentares}

O processo de incorporação de novos alimentos pode ser explicado a partir da perspectiva de Bourdieu e de sua análise cultural mediante o conceito de habitus"1, definido como "um sistema de disposições duráveis e transponíveis que, integrando todas as experiências passadas, funciona a cada momento como uma matriz de percepções, de apreciações e de ações". Este conceito fornece o caminho para a compreensão de que as escolhas individuais são orientadas e permeáveis a transformações sociais advindas, por exemplo, do modo de vida urbano expresso nas diferentes formas de abastecimento e organização do tempo, trabalho e lazer, bem como na individualização do consumo, dentre outras questões. O estudo dos fenômenos sociais deve considerar as complexas relações entre indivíduo e sociedade, nas quais os aspectos sociais, culturais e simbólicos se encontram imbricados.

Deste modo aponta-se a relevância do contexto sociocultural na análise das concepções e práticas alimentares de mulheres de camadas populares.

Examinando as variações de tempo e memória nas narrativas das entrevistadas, duas formas básicas de consumo alimentar foram observadas: uma tradicional, ligada ao manejo da terra, presente na lembrança daquelas que migraram para o Rio de Janeiro; e uma agroindustrial, marcada pela mercantilização do alimento, já articulada aos modos de vida das informantes que viviam na periferia urbana, e inserida aos daquelas que chegaram. Esses dois modelos são aqui considerados de modo não excludentes, sendo apresentados separadamente apenas para efeito de análise. As narrativas apresentam-se heterogêneas, onde para algumas entrevistadas as memórias estavam ligadas à escassez e fome, entretanto para outras, quando as condições financeiras familiares eram melhores, remetiam à fartura tanto nas situações vividas no meio rural ou urbano. Nesta direção é importante sinalizar a expressão destes modos diferenciados de consumo alimentar tendo em vista a delimitação do universo do estudo. 
Não. Não. Se eu disser pra você que eu já passei fome eu tô mentindo. [...] não tinha luxo. [...] Mas comida, nunca faltou não. [...] comia feijão mulatinho [...]. (E1, 45 anos, migrante da zona rural)

[...] Minha mãe fazia uma carne assada com macarronada. Carne assada com feijão bem temperado. [...] Antigamente era muito bom. (E9, 51 anos, nascida na zona urbana)

Macie ${ }^{14}$ aponta que as marcas sociais e culturais relativas à construção indentitária, no que tange à alimentação dos brasileiros, encontram-se relacionadas ao consumo do arroz e do feijão. Quanto às informantes do estudo, a prática alimentar esteve associada ao consumo de feijão de acordo com as variedades regionais. O arroz poderia ainda ser substituído por farinha, mas não o feijão, tendo em vista sua centralidade na categoria "comida". Comida era arroz com feijão, farinha com feijão, ou somente feijão em situações de precariedade alimentar. Todos os outros alimentos que poderiam compor a refeição eram agrupados numa outra categoria chamada 'mistura'. Mistura é um termo que se refere a qualquer preparação à base de ovos, carne, vegetais ou outros alimentos que podem compor uma refeição, sua ausência refere-se a uma alimentação empobrecida ${ }^{15}$. Os relatos evidenciaram, na maioria dos casos, uma condição de não satisfação das necessidades básicas:

Era difícil. Tinha dia que comíamos só feijão e farinha. [...] Sabe, meu avô trabalhava em engenho e quando não tinha mistura, a gente comia arroz, feijão e rapadura. E a gente ficava satisfeito. (E11, 33 anos, migrante da zona rural)

Teve épocas que a situação era bem difícil. [...] Teve dias que a gente passava fome mesmo. [...] (E8, 36 anos, nascida na zona urbana)

A pobreza e a miséria se ligavam objetiva e simbolicamente a uma determinada forma de comer: nem tudo o que alimentava era comida. A noção de alimento estava ligada a qualquer substância nutritiva necessária à sobrevivência, enquanto a de comida estava atrelada a representações sociais e culturais $^{16}$.

a gente comia era inhame de porco... era banana verde. [...] A gente cozinhava pros bichos e tirava para nós... Era mandioca aguada. [...] nós passamos uma vida muito difícil, muito. (E6, 64 anos, migrante da zona rural)

Meu tio trouxe estas coisas da xepa [...]. Aí meu primo fez esta sopa de entulho pra gente comer até que minha mãe voltasse. (E8, 36 anos, nascida na zona urbana)

Estratégias como as descritas acima estão presentes na literatura. Sertanejos em tempos de escassez transformavam alimentos resistentes à seca, que não faziam parte da alimentação cotidiana, em 'iguaria bárbara' para não morrerem de fome ${ }^{17}$. Nesse sentido, o inhame rosa, também conhecido como inhame de porco, foi transformado e apropriado pela cultura como uma 'iguaria bárbara', tendo seu consumo autorizado em tempos difíceis.

O tipo de acesso e os constrangimentos financeiros expressavam ainda classificações e modos de distinção relacionada à condição de pobreza ${ }^{18}$. Comer carne todos os dias separava os pobres dos não pobres. Considerada 'forte' e boa para a saúde, a ausência de carne nas refeições personificava a própria carência ${ }^{15}$. Independentemente do valor nutricional das vísceras, ricas em ferro e fósforo; o consumo de carne, produto caro e de raro acesso, conferia distinção a quem podia adquiri-la.

eu comi muito bofe assado na brasa. Cozido no feijão... tripa de boi, os miúdos do boi... eles matam o boi, tira tudo o que tem dentro do boi... bucho, fígado, coração. Os pessoal da roça, aqueles bem pobrezinho mais... come isso [...]. (E13, 54 anos, migrante da zona rural) 
tipo assim, que fazia qualquer tipo de comida. Assim o necessário, entendeu? Então a gente comia, assim como pobre, mas digno. (E4, 56 anos, nascida na zona urbana)

Trabalhos realizados com populações urbanas entre as décadas de 1970 e 1980 mostram que nas camadas populares a noção de comida também se articulava às categorias saúde e trabalho ${ }^{15}$. A força adquirida por meio da comida forneceria saúde e condição suficiente para a realização das tarefas diárias; assim a pobreza, bem como a doença, estaria ligada à incapacidade de trabalhar e adquirir comida $^{18}$

Nas narrativas das entrevistadas, as memórias do passado destacaram-se enquanto experiências que permitiram a elaboração cultural de um hábito alimentar, cujos códigos regiam um determinado valor simbólico para a comida. Tais aspectos possibilitam a compreensão de como estas práticas se transformaram e se ressignificaram frente às novas demandas de vida em um ambiente de periferia marcado por desigualdade, vulnerabilidade e insegurança. Nesta direção, a noção de habitus como um instrumento conceitual favorece a reflexão sobre a relação entre condicionamentos sociais exteriores e a subjetividade dos sujeitos que coexistem numa intensa relação de interdependência, sendo capaz de expressar o diálogo e a troca constante e recíproca entre as distintas instâncias socializadoras ${ }^{11}$.

Ressalta-se que nos espaços urbanos contemporâneos as condutas sociais delineiam-se por conformações mais individualistas, articuladas a um ritmo de vida marcado pela escassez de tempo ${ }^{19}$. Essas características, associadas ao panorama atual de produção e distribuição de alimentos, favorecem o processo de transição de um padrão alimentar para outro.

\section{Gênero e família}

As práticas descritas pelas informantes colocam em cena um conjunto de movimentos materiais e simbólicos que sustenta a constituição de uma nova identidade, ligada às práticas alimentares e também às transformações na situação social das mulheres ${ }^{20}$.

A demarcação tradicional entre gêneros conferia simbolicamente uma atuação doméstica às mulheres e pública aos homens ${ }^{15}$. A responsabilidade pelo provimento alimentar era um 'dever moral paterno', como apontam os depoimentos, estando intimamente ligado às memórias de privação alimentar. À mulher cabia o exercício de uma economia domiciliar que garantisse a alimentação da família.

Antigamente as coisas eram mais difíceis. Né? E meu pai não deixava minha mãe trabalhar (E18, 48 anos, nascida na zona urbana)

Assim, lembrar [da comida] eu não lembro não. Assim, eu lembro, que eu... meu pai... ele nunca deixou faltar nada pra gente. (E4, 56 anos, nascida na zona urbana)

No entanto, há algumas décadas a porcentagem de mulheres economicamente ativas tem aumentado consideravelmente. É notória uma redução nas diferenças de inserção no mercado de trabalho entre homens e mulheres em todas as formas de ocupação. Em 2003, a proporção de homens com carteira assinada no setor privado era de $62,3 \%$, enquanto a das mulheres era de $37,7 \%$; já em 2011 essas proporções foram de 59,6\% e de 40,4\% respectivamente ${ }^{21}$. Além disso, desde 1980 registra-se um crescimento acentuado nos arranjos familiares nos quais a mulher passou a ser a pessoa de referência, chegando a 38\% em $2012^{22}$. Isso não representou efetivamente uma modificação ou repartição mais igualitária das tarefas entre homens e mulheres ${ }^{23}$ e permite que se compreenda melhor o porquê de uma das entrevistadas, ao pensar seu corpo, referir-se a ele como uma máquina.

não sei... hoje, uma palavra [pensando] caramba... [pensando]. Não sei! Sinceramente não sei... não sei. Talvez uma máquina que não para em momento nenhum: uma máquina que enferruja, mas que ao mesmo tempo não pode parar! (E14, 42 anos, nascida na zona urbana) 
A presença progressiva das mulheres no mercado de trabalho pressiona para que a preparação de alimentos dentro de casa seja mais prática, no sentido de poupar tempo e mão de obra ${ }^{24}$. A sobrecarga causada pela dupla ou tripla jornada de trabalho foi retratada de forma muito emblemática por outra informante.

Primeiro eu levava as crianças e deixava na creche. Quatro e meia eu saia do trabalho pra passar na creche e pegar eles às cinco horas [...]. Levava pra casa, deixava eles brincando com alguma coisa, vendo televisão... la, botava roupa de molho, [...] lavava roupa na mão. [...] Aí fazia comida, aí já fazia marmita dele (do marido), botava na geladeira. Aí a gente jantava e já ia dormir, os meninos também, porque acordava cedo pra ir pra escola. (E3, 43 anos, migrante da zona rural)

O acúmulo de tarefas restringe o tempo disponível para o preparo da alimentação da família. Essa falta de tempo é um aspecto importante da reestruturação das práticas e explica, em parte, o aumento do consumo dos alimentos ultraprocessados ${ }^{25}$.

Independentemente de classe social, ao longo das últimas décadas a população brasileira substituiu alimentos isentos de processamento e/ou industrializados por alimentos ultraprocessados ${ }^{26}$. Estes produtos apresentam características desfavoráveis do ponto de vista nutricional por serem formulações industriais compostas em grande parte, se não inteiramente, por óleo e gordura, inclusive hidrogenada, açúcar, amido modificado, corantes, aromatizantes e realçadores de sabor, possuindo maior densidade energética, teor de açúcar, gordura, sódio e potássio e menor teor de fibras que os alimentos industrializados com menor processamento ${ }^{27}$. Entretanto, são palatáveis, acessíveis financeiramente e duráveis, do ponto de vista do tempo de armazenamento, apresentando-se como opções rápidas de consumo.

A praticidade do alimento é um aspecto fundamental no cotidiano das informantes. A busca por economia de tempo fomenta modificações nos modos tradicionais de preparo das refeições, sendo potencializada por meio do aumento no consumo de bens duráveis viabilizando o uso de equipamentos como, por exemplo, o forno de micro-ondas nas camadas populares ${ }^{28}$.

eu trabalho fora e tem que ser uma coisa prática. [...] mas aí eu faço arroz de micro-ondas. (E15, 29 anos, nascida na zona urbana)

Morar sozinha, com o cônjuge, ou com filhos únicos diminui a frequência do preparo de refeições no domicílio, aumenta a flexibilidade das escolhas e favorece o consumo de alimentos industrializados de baixo valor nutricional.

Por conta disso que eu parei de fazer comida em casa. Porque eu fazia comida em casa, trazia minha marmita e a comida ficava rolando dois, três dias na geladeira. [...] Aí eu falei: não vou mais fazer comida em casa, e como sempre na rua. (E21, 57 anos, migrante da zona rural)

Esse relato está ligado à tendência demográfica associada à queda da taxa de fecundidade, sobretudo nas cidades e nas regiões mais desenvolvidas, onde ocorreu uma redução do peso relativo dos arranjos familiares constituídos por casais com filhos ${ }^{22}$. Menor número de dependentes, jornadas de trabalho no fim de semana e outras circunstâncias diminuem a regularidade da realização de refeições como forma de convívio familiar.

Assim... é complicado, principalmente no final de semana. Porque eu saio para trabalhar na sexta e só volto na segunda. (E11, 33 anos, migrante da zona rural)

Quando a gente tá em casa todo mundo come, mas às vezes cada um come num horário. Às vezes meu filho vai pra casa da namorada e não tem hora pra chegar. (E2, 53 anos, migrante da zona rural) 


\section{Práticas alimentares e consumo de bens materiais e simbólicos}

Como já assinalado, a introdução dos alimentos industrializados, principalmente dos ultraprocessados, liga-se à necessidade de rapidez e praticidade no cotidiano. Classificados anteriormente como 'supérfluos' esses produtos não faziam parte da categoria "comida", representada pelo arroz e/ou farinha com feijão ${ }^{15}$.

(E as compras então?) É o básico: é biscoito, é banana, é miojo; coisas assim bem práticas, bem práticas. (E1, 45 anos, migrante da zona rural)

O desenvolvimento de determinado gosto mantém íntima ligação com as pressões materiais e urgências temporais inscritas nas condições objetivas de existência ${ }^{11}$. Na configuração da vida contemporânea os alimentos ultraprocessados foram ressignificados social e culturalmente, integrandose ao hábito como "alimentos básicos". Seu consumo expressa, para além de adequação econômica ligada às necessidades de classe, transformações no gosto que distinguem os diferentes grupos, como analisa Bourdieu ${ }^{11}$.

As narrativas ainda apresentam conflitos e oscilações na forma de construir representações acerca dos alimentos industrializados, principalmente dos ultraprocessados. Acontece que apesar da forte conotação negativa, eles fazem parte do cotidiano e do gosto alimentar das informantes e para serem ingeridos exigem estratégias de preparo que diminuam o peso simbólico ligado a essa qualidade de produtos.

Final de semana é o dia do lixo na janta. Da pizza, da lasanha, do industrializado. Lasanha de caixinha, cachorro quente, refrigerante. (E8, 36 anos, nascida na zona urbana)

Eu compro miojo pro meu filho, mas não uso o tempero... tipo miojo com caldo de feijão. [...] se eu não fizer assim, acaba eu não fazendo comida, acaba eu comendo besteira. (E15, 29 anos, nascida na zona urbana)

Há um excesso de informações, muitas vezes contraditórias, que se ligam ao 'comer'. Esta situação promove uma desestabilização de antigas certezas, mas também mudanças; promovendo insegurança em relação às escolhas, situação denominada por Fischler como gastro-anomia ${ }^{29}$.

Antigamente eu comia muito arroz e pouco feijão. Agora não, eu como menos arroz e mais feijão... entendeu? E assim... às vezes eu como arroz, não como batata... Mas eu vim de uma família de poder comer tudo... né? De poder comer tudo. (E4, 56 anos, nascida na zona urbana)

Por exemplo, eu amo arroz. Mas o arroz engorda [...] o outro (se referindo ao integral) também engorda. (E6, 64 anos, migrante da zona rural)

Calvo ${ }^{30}$ sistematizou três caracterizações sobre os modos de ocorrência das mudanças das práticas alimentares, assim compreendidas: a primeira está relacionada à presença de uma dicotomia na qual novas práticas são adotadas, ainda que se mantenham as antigas, adaptadas; a segunda apresenta uma maior perda de referência das tradições e ao mesmo tempo, uma menor autonomia das escolhas, já que se mantém em estreita dependência dos especialistas e com significativo risco de desequilíbrio alimentar; enquanto a terceira é caracterizada por uma desestruturação dos elementos de origem, ligada normalmente a uma desvinculação sociocultural e à precariedade econômica, sem que se reconstrua organizadamente um novo padrão alimentar. Nesta direção, a desorganização dos sistemas normativos e de controle social que regulam tradicionalmente as práticas alimentares se liga contemporaneamente a uma série de problemas complexos, dentre os quais se destacam o crescimento alarmante dos indicadores de sobrepeso e obesidade que juntos atingem quase $60 \%$ 
da população adulta brasileira e o aumento dos indicadores de sofrimento psíquico e de transtornos alimentares ${ }^{31,32}$.

Ligados às transformações alimentares estão os diferentes discursos que se associam a ela, principalmente os que se ligam à saúde, longevidade e beleza ${ }^{33}$. Sobretudo entre as mulheres, em geral mais inquiridas em relação às variações de peso, não só por questões de saúde, mas pelas questões culturais implicadas na construção de imagens em torno do corpo ideal na cena contemporânea. É interessante ressaltar o quanto antinomias como saúde/indulgência e conveniência/cuidado atravessam contemporaneamente o processo de seleção e escolha alimentar ${ }^{34}$. Apesar de produzidos socialmente, esses discursos se disseminam midiaticamente, atingindo de distintas maneiras diferentes grupos sociais. Essa situação evidencia sua face mais perversa em populações vulneráveis, nas quais instalam dúvidas e insegurança inclusive em relação a alimentos que fazem parte da sua herança cultural.

A categorização dos alimentos previamente estabelecida por uma rede de significados nas classes sociais de menor poder aquisitivo é adicionada das novas incorporações alimentares e se sobrepõe ao discurso de promoção da saúde, exigindo ressignificações contínuas articuladas à singularidade individual das informantes. A orientação nutricional de que se deve privilegiar a escolha de alimentos ricos em fibras, vitaminas e minerais está significativamente disseminada no senso comum, mas se confronta, por exemplo, com representações ainda muito presentes de que alimentos como verduras, legumes e frutas não fornecem a força necessária ao trabalho por não serem "comida".

Porque eu realmente não guento: eu tenho que comer bem. Eu tenho que comer. Se eu não comer meu feijão com arroz. Eu tenho que comer... se eu não comer eu passo mal. Eu te falei, eu pego é panela de $50 \mathrm{~kg}$, é panela que nem homem... Quer dizer... é serviço braçal mesmo. (E1, 45 anos, migrante da zona rural)

A implicação do discurso que idealiza um modelo de alimentação saudável e que desconsidera as várias dimensões relativas ao hábito alimentar, se mescla com recomendações voltadas a um padrão estético, abrindo espaço para um amplo mercado de consumo. Comercializam-se uma série de produtos e programas que não medem consequências na promessa da conquista de saúde e geram demandas de consumo. Alimentos introduzidos em práticas, que muitas vezes não se sustentam por muito tempo, são substituídos a cada nova publicação transformada em reportagem especial de televisão ou apropriada e comercializada pela indústria alimentícia ${ }^{35}$. Processo que junto à precariedade econômica dificulta a reconstrução de um padrão alimentar seguro do ponto de vista nutricional.

Quando eu vou pra Bonsucesso eu passo na loja. As pessoas falando das dietas... Eu vou e leio: sucos que curam! Água de berinjela, limão e gengibre... Aí vejo lá... Suco de melancia... Eu falo: vou fazer. Sei o que as pessoas ficam falando dessas dietas rápidas. Aí compro a melancia. [...] Chás que curam: eu comprei camomila, tinha um que tinha que tomar antes de dormir... Olha eu tomava limão com café quando eu trabalhava e tomava... [...] Na hora do almoço, eu ia almoçar, eu botava saladinha, elas (as colegas de trabalho) botavam só a carne... Só que a hora que chegava em casa estava com fome. (E13, 54 anos, migrante da zona rural)

Os aspectos que diferenciam as práticas alimentares das informantes que seguem determinadas lógicas consideradas saudáveis, daquelas que se desvencilham deste padrão de consumo estão ligados às singularidades individuais e a crenças nas propriedades dos alimentos, bem como à noção de moralidade e à própria relação com o corpo, dentre outras questões.

eu sempre tive paranoia de saúde, então porque eu acho que é por conta mesmo de gostar da área de saúde, né? Então eu sempre acompanhei... lá em casa eu tenho uma pasta cheia de recortes, de receitas light, recortes de dietas, de dicas. Por exemplo, eu parei de tomar refrigerante porque eu li um artigo no jornal que tava dizendo que o refrigerante ele corta, ele impede o organismo de absorver os nutrientes. Então eu falei: eu não vou mais tomar. Porque 
se eu como pra manter meu organismo bom, eu tomo um negócio que vai broquear. Eu tô fazendo o que? É a mesma coisa de fumar. Só prejudica então eu não quero consumir nada que me prejudica. (E21, 57 anos, migrante da zona rural)

As práticas alimentares das mulheres entrevistadas estão articuladas em conformidade com a vida em família, situações de trabalho e socioeconômicas próprias do grupo que dão sentido às escolhas e a imagem que atribuem a si mesmas. Ressalta-se que as escolhas e práticas não nascem no indivíduo, elas surgem e são transformadas nos processos e interações sociais. Assim quando um indivíduo exercita sua preferência, ele o faz dentro de um quadro de possibilidades moldado tanto por aspectos micro quanto macrossociais, que fornecem as alternativas alimentares dentre as quais é possível escolher. Em síntese, distintas instâncias socializadoras e referências indentitárias coexistem no mundo contemporâneo e modelam as concepções e as práticas alimentares individuais. Referências ligadas à experiência escolar, ao trabalho, à família e à localidade - mas também à mídia, se interpenetram em um espaço dinâmico constitutivo das relações sociais que, no entanto, não podem ser concebidos de modo antagônico à construção da imagem e experiência de si, ao processo de individualização e, em suma, aos recursos e às trajetórias particulares ${ }^{11}$.

\section{Considerações finais}

No que se refere à alimentação, a realidade cotidiana das mulheres entrevistadas é marcada pela escassez de tempo e vinculada à relações de gênero. As novas formas de inserção das mulheres no mercado de trabalho não retiraram sua centralidade no cuidado doméstico, conduzindo-as à procura de praticidade e favorecendo o consumo de alimentos industrializados, principalmente ultraprocessados. Esse processo produz a desestruturação dos padrões alimentares anteriores, tendência que, associada a constrangimentos financeiros, dificulta a construção de modos de consumo nutricionalmente seguros.

As narrativas das mulheres apresentam contradições, oscilações e sobreposições próprias de um processo de transformação e ressignificações que caracterizam a formação de um habitus que, por um lado, absorve discursos sobre o que seria uma alimentação saudável e, por outro, se realiza de acordo com disponibilidades que contradizem as "boas práticas" enunciadas por diferentes discursos: o científico, o das intervenções no campo da saúde e o da mídia. Há uma polifonia de discursos ligados à alimentação que, dentre outras questões, amplificam demandas de mercado. Este se retroalimenta destes diferentes discursos e promove a incorporação de produtos que sejam práticos, baratos, palatáveis, mas sabidamente danosos; ou de outros cujas alegações recaem na ideia de trazerem benefícios para a saúde ou estéticos, advindos com o emagrecimento. Em geral, as mulheres entrevistadas percebem, mas não apresentam uma elaboração clara de distinção entre sua realidade concreta e uma perspectiva idealizada do que seja "bom". Elas convivem com o resultado de suas impossibilidades de consumo e da (re)construção do "gosto" em relação ao comer de acordo com as normas prescritivas do que seja uma "alimentação saudável".

Essas questões devem ser observadas na elaboração das abordagens de intervenção no nível individual, pois este é indissociável da existência coletiva e das condições materiais e existenciais. Assim, ao se considerar tais condições, e o fato delas modularem concretamente as possibilidades de aquisição e consumo, abre-se espaço, sobretudo no campo da saúde, para a produção de formas mais consistentes e criativas de proteção, valorização e ação junto aos grupos sociais.

Nesta direção, destaca-se também a necessidade de aperfeiçoamento das ações governamentais regulatórias em relação à produção, comercialização e divulgação de produtos comprovadamente danosos à saúde humana, bem como o fomento a formas de produção agrícola contra hegemônicas, de modo a ser possível promover processos de produção e comercialização mais sustentáveis. $O$ acesso à informação, embora imprescindível, não garante sozinho a realização de práticas alimentares consideradas saudáveis. Como sugerem os dados da pesquisa, faz-se necessário problematizar a interferência destes amplos condicionantes na margem de liberdade das decisões individuais. 


\section{Colaboradores}

Oliveira TC e Czeresnia D participaram desde a concepção e desenho do estudo até a redação e aprovação da versão final do artigo. Vargas EP colaborou na análise e interpretação dos resultados, escrita e aprovação da versão final do artigo. Barros DC colaborou na discussão dos resultados e aprovação da última versão do artigo.

\section{Referências}

1. Oliveira SP, Thébaud-Mony A. Modelo de consumo agro-industrial: homogeneização ou diversificação dos hábitos alimentares? Rev Cad Debate. 1996; 4:1-13.

2. Fonte M. Food Systems: consumption models and risk perception in late modernity. Int J Soc Agric Food. 2002; 10(1):13-21.

3. Giddens A. As consequências da modernidade. São Paulo: UNESP; 1991.

4. IBGE. Coordenação de Trabalho e Rendimento. Pesquisa Nacional de Saúde. Acesso e utilização dos serviços de saúde, acidentes e violências: Brasil, grandes regiões e unidades da federação. Rio de Janeiro: IBGE; 2015. 100 p.

5. Schmidt MI, Duncan BB, Azevedo e Silva G, Menezes AM, Monteiro CA, Barreto SM, et al. Chronic non-communicable diseases in Brazil: burden and current challenges. Lancet. 2011; 377(9781):1949-61.

6. Canella APB, Claro RM, Moubarac JC, Baraldi LG, Cannon G, Monteiro CA. Ultra-processed food products and obesity in Brazilian households (2008-2009). Plos One. 2014; 9:927-52.

7. Arnaiz MG. Maneiras de comer hoy. Rev Int Sociol. 2005; 40:159-82.

8. Moore S, Hall JN, Harper S, Lynch JW. Global and national socioeconomic disparities in obesity, overweight, and underweight status. J Obes. 2010; 10:1-11.

9. Paeratakul S, Lovejoy JC, Ryan DH, Bray GA. The relation of gender, race and socioeconomic status to obesity and obesity comorbidities in a sample of U. S. adults. Int J Obes Relat Metab Disord. 2002; 26:1205-10.

10. Hoffmann R. Condicionantes do sobrepeso e da obesidade de adultos no Brasil, 2008-2009. Seg Alimen Nutr. 2012; 19(2):1-16.

11. Bourdieu P. Questões de sociologia. Rio de Janeiro: Marco Zero; 1983.

12. Minayo MCS. O desafio do conhecimento. Pesquisa qualitativa em saúde. 9a ed. São Paulo: Hucitec; 2006.

13. Fontanella BJB, Ricas J, Turato ER. Amostragem por saturação em pesquisas qualitativas em saúde: contribuições teóricas. Cad Saude Publica. 2008; 24 (1):17-27.

14. Maciel ME. Cultura e alimentação ou o que têm a ver os macaquinhos de Koshima com Brillat-Savarin? Horiz Antropol. 2001; 7(16):145-56.

15. Zaluar A. A máquina e a revolta. As organizações populares e o significado da pobreza. $2 a$ ed. São Paulo: Brasiliense; 1994.

16. DaMatta R. O que faz o brasil, Brasil? Rio de Janeiro: Rocco; 1986.

17. Castro J. Geografia da fome. 5a ed. Rio de Janeiro: Civilização Brasileira; 2005. 
18. Canesqui AM. Mudanças e permanências da prática alimentar cotidiana de famílias de trabalhadores In: Canesqui AM, Garcia RWD, organizadores. Antropologia e nutrição: um diálogo possível. Rio de Janeiro: Fiocruz; 2005.

19. Garcia RWD. Práticas e comportamento alimentar no meio urbano: um estudo no centro da cidade de São Paulo. Cad Saude Publica. 1997; 13(3):455-76.

20. Araújo C, Scalon C. Gênero e a distância entre a intenção e o gesto. Rev Bras Cienc Soc. 2006; 21(62):45-68.

21. Instituto Brasileiro de Geografia e Estatística. Síntese de indicadores sociais. Uma análise das condições de vida da população brasileira. Rio de Janeiro: IBGE; 2013.

22. Monsivais $P$, Aggarwal A, Drewnowski A. Time spent on home food preparation and indicators of healthy eating. Am J Prev Med. 2014; 47(6):796-800.

23. Instituto Brasileiro de Geografia e Estatística. Pesquisa mensal de emprego. Mulher no mercado de trabalho: perguntas e respostas. Rio de Janeiro; 2012 [citado 17 Set 2015]. Disponível em: http://www.ibge.gov.br/home/estatistica/indicadores/ trabalhoerendimento/pme_nova/Mulher_Mercado_Trabalho_Perg_Resp_2012.pdf.

24. Neves MA. Anotações sobre trabalho e gênero. Cad Pesqui. 2013; 43(149):404-21.

25. Jabs J, Devine CM. Time scarcity and food choices: an overview. Appetite. 2006; 47(2):196-204.

26. Monteiro CA, Levy RB, Claro RM, Castro IR, Cannon G. Increasing consumption of ultra-processed foods and likely impact on human health: evidence from Brazil. Public Health Nutr. 2011; 14(1):5-13.

27. Louzada MLC, Martins APB, Canella DS, Baraldi LG, Levy RB, Claro RM, et al. Alimentos ultraprocessados e perfil nutricional da dieta no Brasil. Rev Saude Publica. 2015; 49:38.

28. Yaccoub H. A chamada "nova classe média" : cultura material, inclusão e distinção social. Horiz Antropol. 2011; 17(36):197-231.

29. Fischler C. Gastro-nomie et gastro-anomie. Communications.1979; 31(1):189-210.

30. Calvo M. Migration et alimentation. Soc Sci Inform. 1982; 21:383-446.

31. Instituto Brasileiro de Geografia e Estatística. Pesquisa Nacional de Saúde. Ciclos de vida: Brasil e grandes regiões. Coordenação de Trabalho e Rendimento. Rio de Janeiro: IBGE; 2015.

32. Nunes $M O$, Bittencourt $L$. No rastro do que transtorna o corpo e desregra o comer: os sentidos do descontrole de si e das "compulsões alimentares". Interface (Botucatu). 2013; 17(44):145-57.

33. Kraemer FB, Prado SD, Ferreira FR, Carvalho MCVS. O discurso sobre a alimentação saudável como estratégia de biopoder. Physis. 2014; 24(4):1337-60.

34. Warde A. Consumption, food and taste: culinary antinomies and commodity culture. London: Sage Publications; 1997.

35. Freitas RF, Ferreira FR, Carvalho MCV, Prado SD, organizadores. Corpo e consumo nas cidades. Curitiba (PR): CRV; 2014. v. 2. 
Oliveira TC, Czeresnia D, Vargas EP, Barros DC. Concepciones sobre prácticas alimentarias en mujeres de clases populares en Río de Janeiro, Estado de Río de Janeiro, Brasil: transformaciones y resignificaciones. Interface (Botucatu). 2018; 22(65):435-46.

En este estudio de cuño cualitativo se buscó entender las concepciones y los sentidos atribuidos a las prácticas alimentarias en mujeres de clases populares con exceso de peso. Cuestiones asociadas a las condiciones sociales y culturales de la vida urbana configuran un proceso de transformaciones señalado por la escasez de tiempo y la búsqueda de la practicidad. Produtos ultra procesados, antes considerados superfluos, son ahora considerados básicos en la alimentación de este grupo. Esa realidad se confronta con el discurso contemporáneo de la alimentación saludable que, al fomentar una demanda de consumo de productos considerados benéficos para la salud, exige de las informantes constantes re-significaciones con relación al "comer" que oscilan entre el placer y la culpa. Se discute la necesidad de comprender tales expresiones dentro de un cuadro de posibilidades restringido y determinado por aspectos micro y macro sociales que conforman los modos contemporáneos de producción y distribución de alimentos en nuestra sociedad.

Palabras clave: Prácticas alimentarias. Cultura. Exceso de peso. 